REVIEW

\title{
Streets of Paris, sunflower seeds, and Nobel prizes. Reflections on the quantitative paradigm of public health
}

\author{
Johan P Mackenbach
}

J Epidemiol Community Health 2004;58:734-737. doi: 10.1136/jech.2003.016139

Quantitative methods are central to public health and public health research. The historical roots and philosophical foundations of this predilection for the quantitative, however, are little known and seldom discussed.

Correspondence to: Professor J P Mackenbach, Department of Public Health, Erasmus MC, University Medical Center Rotterdam, PO Box 1738 3000 DR Rotterdam, Netherlands:

j.mackenbach@

erasmusmc.nl

Accepted for publication 3 December 2003

\section{THE STREETS OF PARIS}

C ituated at the highest point of the "rive gauche" in Paris is the Panthéon, an edifice built in the classical style that forms the final resting place of the heroic sons of France. Inside the building, under a central dome some 60 metres high, is a copy of Foucault's pendulum. This is a small but heavy weight on a long steel cable that leisurely swings back and forth, and if one watches long enough, it can be seen that the pendulum appears to be rotating very slowly. "Appears" to be rotating, because it is in fact the floor under the pendulum that is turning-rotating with the earth, while the pendulum continues to swing in exactly the same direction. This is a brilliant demonstration of the rotating movement of the earth, used by Foucault to provide its first scientific proof in 1851. Or, in slightly different words: while the motion of the earth occurs on a scale that does not affect our perception of movement, it is clearly visualised by means of Foucault's pendulum on a few square metres of marble floor. ${ }^{1}$

Under the floor is the crypt of the Panthéon, accommodating the vaults of important French statesmen, philosophers, and writers, as well as those of a number of men of science, the latter dating mainly from the end of the 18th and the first half of the 19th century. Among these are a remarkable number of mathematicians, including Lagrange, Condorcet, and Monge. Thanks to Lagrange, renowned for the publication of the first systematic theory of functions, we are able to formulate regression equations. Condorcet became famous for his work on the probability of majority decisions, after which he himself literally fell victim to such a majority decision during the French revolution. Monge is the founder of modern geometry. ${ }^{2}$

A street has been named after each of these men in Paris, as well. More precisely, there are over 100 streets in Paris named after mathematicians. Next to the three aforementioned names, that of a figure well known to epidemiologists and public health researchers generally can also be found on the city plan, namely Poisson, one of Lagrange's students (fig 1). Regretfully, his street is only a small one, nor has Poisson-unlike his master-been "pantheonised", as the French would say.

Modern day public health researchers are, for the most part, unaware that the origins of the application of quantitative methods in public health lie in France. Most historical treatises in the field of public health fail to look beyond the Anglo-Saxon nose of the author, and ascribe the roots of these methods to English pioneers, such as Farr and Chadwick, who in the third and fourth decades of the 19th century published their famed quantitative analyses of the poor health conditions in the major cities of England. Both, however, were building on the work of French researchers in the 1820s, such as Villermé. We know that Farr studied in Paris under Pierre Louis, who laid the foundation for the "numerical method" in medicine. Chadwick quotes extensively from the work of his French predecessors, for example when dealing with the need for public responsibility in sanitation issues and the necessity of laying sewerage systems. ${ }^{3}$

The idea that sanitation was not merely a private matter, but rather an issue for the public authorities had emerged shortly before and during the French Revolution. This notion reflects something of the rabid Enlightenment way of thinking that also produced the guillotine-a scientifically efficient method to cut opponents down to size. The very same way of thinking led to numerous drastic reform proposals in public health, which, while amounting to very little during those chaotic years, would none the less later give rise to the foundation of the first public health institutions in Europe. France was also the first to have a public health journal: the Annales d'Hygiène Publique, which for the first time appeared in 1829, and still exists, albeit without an impact factor. ${ }^{4}$

This brief historical detour provides some insight into the backgrounds of how the quantitative approach came to be used in public health issues. Application of the numerical method in health issues was an innovation that arose at the teaching hospitals of Paris in the early 19th century; it was used to systematise patient observations. It merged careful observation with mathematical reasoning, and can be seen as an attempt to reconcile "rationalism" with "empiricism". It applied Cartesian principles: the

This paper is based on a New Year's dinner's speech, held for the Department of Public Health at Erasmus Medical Center in January 2003. 


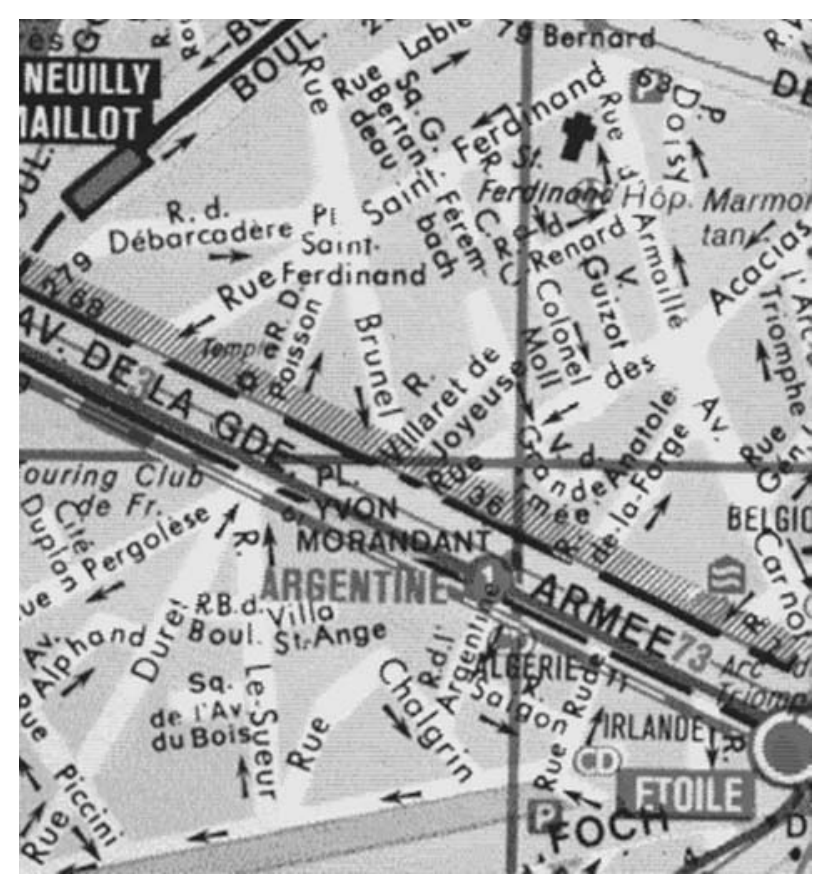

Figure 1 Part of the street plan of Paris, showing the street named after Poisson slightly above, and to the left of, the middle.

conviction of Descartes and other French and continental philosophers, that our senses are deeply fallible, and that observations are solely reliable when supported by the fundaments of infallible mathematics.

At the same time, it also followed the principle of "empiricism", a philosophical doctrine that relied wholly on observations, and that mainly gained a following in phlegmatic Britain. Even today, and despite successful merging in contemporary scientific methods, traces of this great divide can still be found in medicine. It is no coincidence that Cochrane, the great propagandist of randomised controlled trials (RCTs), whose name lives on in the Cochrane Collaboration, was British. In France, far less value is attached to the results of RCTs, and official approval procedures for drugs are partly based on the reasoning that a drug derived from a sound theory must work, regardless of the outcomes of empirical studies. ${ }^{6}$

Some of this old dichotomy between rationalism and empiricism also resurfaces in today's discussions about the scientific status of mathematical models in public health research. There will always be those who, in the case of variations between the results of a well argued model and those of empirical observations, give priority to the former, while others will be more likely to discard the model, however elegant.

\section{COUNTING SUNFLOWER SEEDS}

Confronted with sunflowers most people will be reminded of the huge fields in the south of France, of genetically modified or unmodified sunflower oil, or of Van Gogh's famous paintings-but many mathematicians will automatically think of Fibonacci numbers. Anyone taking the time to inspect the seeds in the heart of the sunflower will notice that they are ordered in two sets of spirals-one clockwise, the other anticlockwise (fig 2). Some sunflowers have 21 spirals that are clockwise and 34 anticlockwise; others have 34 spirals running in clockwise direction and 89 anticlockwise, 55 clockwise and 89 anticlockwise, or 98 in clockwise direction and 144 anticlockwise. Old hands will immediately note that 55 is the sum of 21 and 34, 89 the sum of 35 and 55,

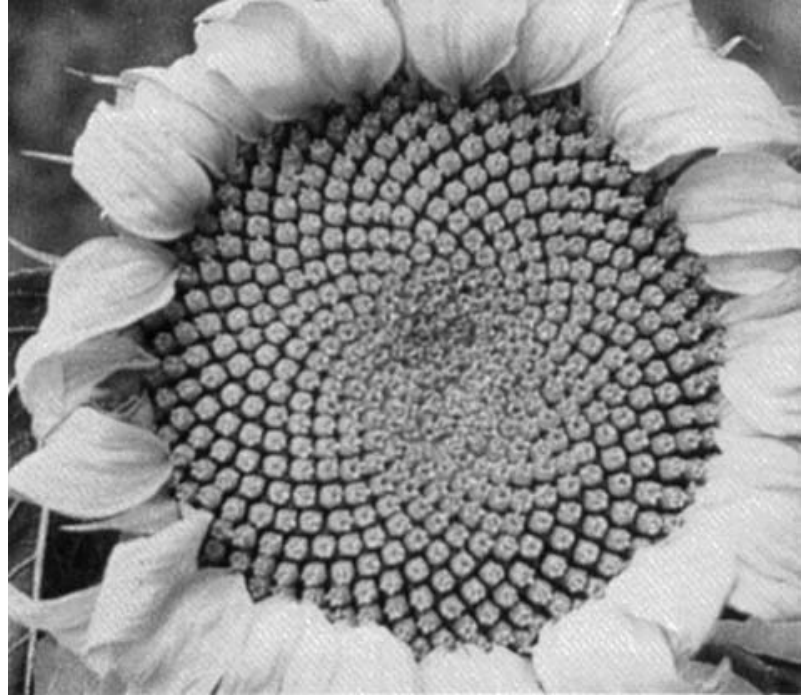

Figure 2 Sunflower with 21 and 34 spirals of seeds.

and 144 the sum of 55 and 89, which brings us to what is so special about these numbers: they are all numbers in the Fibonacci sequence. $^{8}$

Fibonacci was an Italian mathematician around the time that Arabic numerals were gaining recognition in Western Europe, approximately the year $1200 .^{9}$ He was inordinately fascinated by the mathematical tricks that were possible using the nifty new numbers, wrote a book dealing with calculations, and discovered the numbers sequence that was later named in his honour. The series is $0,1,1,2,3,5,8,13$, $21,34,55,89,144, \ldots$, where every number is the sum of the two preceding numbers. This sequence was a mathematical model that provided a more or less realistic description of the growth of rabbit populations; it was probably even one of the very first mathematical models, in this case applied to a demographical phenomenon.

What makes this series so extraordinary is that it not only applies to breeding rabbits, but also describes numerous botanical phenomena, such as the spiralled ordering of the sunflower seeds, but also that of the scales of pineapples, and the number of petals produced by flowers. Nearly all flowers produce a petal number belonging to the Fibonacci sequence: $3,5,8,13,21,34,55,89$. Lilies have 3, buttercups 5, delphiniums have 8 , marigolds 13 , asters 21 , and daisies 34 , 55 , or $89 .^{8}$

In those who are mathematically inclined this regularity gives an experience of beauty unmatched by anything a Van Gogh can provide. Condensing reality into a simple but elegant formula: this is surely the pinnacle in science? And is not parsimony a sign of the truth? The simpler the formula, the more fundamental does the law we are seeking appear to be. Only recently, in 1992, was the mechanism behind this natural pattern in botany unravelled. The cells in the germinating part of the plant are ordered in Fibonacci spirals, because on dividing, they are pressed into a certain angle, the so called golden angle of 137.5 degrees. Only at this angle will there be no open spaces between the cells after division. This geometric principle of efficient space utilisation therefore governs the production of sunflower seeds, pineapple scales, and flower petals. ${ }^{8}$

The mathematics of the living world are truly a marvel, and fascinating examples abound: the striped patterns in the coats of zebras and tigers, the gossamer lines of spiders' webs, shells, the growth of bacteria and broccoli, the sine and cosine of breathing, the coiling of a snake... All are patterns 
that can be reduced to mathematical formulas, can therefore be simulated on the computer, and are based on the fact that living nature utilises the laws of lifeless nature that have for so much longer been described in mathematical terms. Astronomy, optics, geography are all inconceivable without mathematics, nor would Foucault have ever been able to devise his experiment with the pendulum without the mathematics of circle and gravity.

It becomes even more fascinating when the partly biological, partly social processes determining the health of populations are also found to conform to simple mathematical formulas. The application of the numerical method in public health often does not go beyond a little addition, subtraction, division, and multiplication. However, the rare moments that we detect patterns that can be described by a mathematical formula fill us with a sense of being close to a deep truth. There are many examples: from the pattern of the spreading of infection to the rise and fall of the ischaemic heart disease epidemic, and from seasonal variation in disease rates to the rise in mortality rates with age. ${ }^{10}$

This last example is one of the best- the regularity in the increase in mortality rates with age indicates that even life and death are governed by the elegant laws of mathematics. It was a contemporary of Lagrange, Condorcet, and Monge, called Gompertz who formulated a "law of mortality". Benjamin Gompertz was an actuary of Dutch descent who applied mathematical principles to life assurance while working in London. He discovered that, at least from around the age of 20, the risk of dying doubled with every eight years lived. He described this phenomenon in a simple formula and discovered that the same formula not only applied to Britain, but to other countries as well. ${ }^{11}$ Even today, the doubling of risk in eight years still holds, even though the basic mortality rate has fallen strongly because of the higher level of prosperity, public health measures, and improvements in health care. ${ }^{12}$

Gompertz was convinced that this formula contained a fundamental truth about life and death, but was unable to unravel this. Later, other researchers found exponentially increasing mortality figures with age for other species as well, although different lengths of time in which the risk doubles apply. The mortality figures are lowest for any species around the age of sexual maturity, and subsequently increase faster with age the shorter the reproductive period. What is the deeper truth behind this? According to those who have studied the phenomenon, the message contained in this pristine pattern is that we die because we are finished with sex, and that external life is solely attainable via reproduction. ${ }^{13}$ Probably, just like the mathematical model behind sunflower seeds, it is all a matter of efficient utilisation of space, energy or both.

\section{THE IRONY OF NOBEL PRIZES}

Public health goes beyond the experience of beauty and the consoling thought: the knowledge we acquire using our quantitative methods must be applied in practice. However, it is at this point that we run up against an extremely annoying problem: many people cannot understand our figures, and even when they can, they refuse to act accordingly.

Innumeracy takes many forms, and the causes are likely to be complex. ${ }^{14}$ It is not always merely a question of not being able to do arithmetic, although that may also play a part. The difficulty of understanding why, if you add 50\% to something and then subtract $50 \%$, you do not end up with the same number you started out with, is not necessarily caused by dumbness. Arithmetical operations that are more complicated than simple addition or subtraction just do not correspond with the operations that we apply in reasoning and deliberation. This is caused by the fact that the latter consist of words, which we tend to subject to "linguistic" rather than mathematical operations.

Another difficulty is that it is hard for most people to imagine very big and very small numbers. And these are what we use most in public health: we talk about large numbers of cases of disease and about small risks, but most people have no mental image of the numbers concerned. Almost no one can summon a concrete image of numbers that are larger than 1000 or smaller than one hundredth, ${ }^{14}$ and it is therefore hardly surprising that our message does not always find a fertile reception. In that sense, we lack a tangible example of the kind provided by the pendulum of Foucault, which can demonstrate a movement on cosmic scale on the ground beneath our feet.

And then the calculation and interpretation of risks: despite 200 years of probability calculation, very little of this has penetrated the everyday thinking of the population at large. For many people, the reality of the 80 year old smoking grandfather looms far larger than the calculations of probability made by epidemiologists about the health risks of certain dietary habits or environmental factors. Hence smokers may well have a fear of flying, and doctors may be of the opinion that the negative effects of a drug trial do not apply to their patients. This is the world in which public health experts must peddle their wares: telling people that they should not smoke and eat a more nutritious diet, telling policymakers that the breast cancer screening programme should definitely be continued or not, and that the cholesterol guideline is wrong, all the while keeping a cool head and awaiting the latest refinement in the calculation that can make all the difference...

That gap between the straightforwardness of infallible mathematics and the apparent twists and turns in the reasoning of those of mere flesh and blood is not only sadly

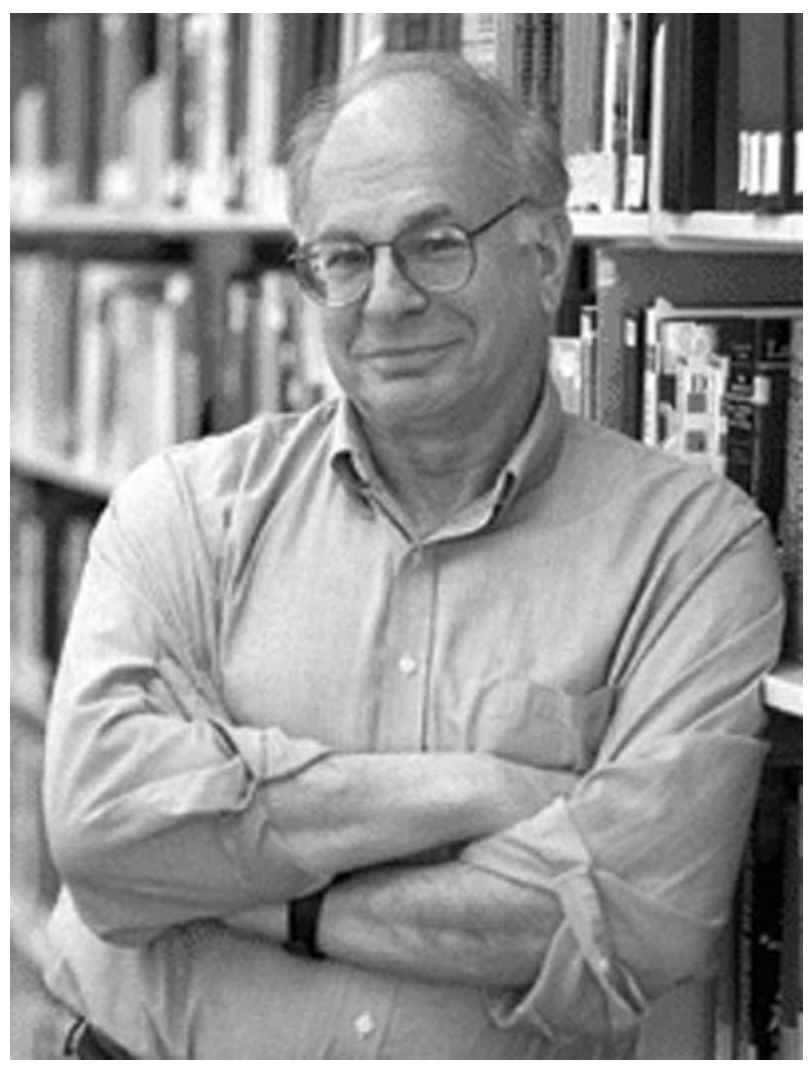

Figure 3 Daniel Kahneman, winner of the 2002 Nobel prize for economics. 
persistent, it has even given rise to new areas of research. It is undeniably clever of us researchers first to invent the concept of risk, and then, on discovering that people are slow to pick up on this, to ensure additional years of work under the flag of the new concept of "risk perception". It is therefore ironic that a Nobel prize can be won for research into the numerical ignorance of ordinary people, as in Kahneman's case in 2002 (fig 3). ${ }^{15} \mathrm{He}$ demonstrated in a number of rightly famous studies that people find small risks and big numbers very difficult and that they are extremely inconsistent when it comes to weighing advantages against disadvantages: the probability of a loss is weighed much more heavily than an equally large probability of an equally large benefit, which makes behavioural choices regarding health and disease appear irrational. ${ }^{16}$

\section{BY WAY OF CONCLUSION}

Trust in quantitative methods is part of the "paradigm" of public health, ${ }^{17}$ and some of the most resounding successes achieved by public health may be directly attributed to meticulous counting and calculating. One example that immediately leaps to mind is that of the paradigmatic John Snow, who tracked down the contaminated water pump in Broad Street by counting cholera patients in the streets of London. This predilection for the quantitative is, on the face of it, perfectly understandable, because how could we ever draw any kind of conclusions about population health without counting and calculating the number of individuals who are ill?

There is more to it than that alone, however, as the above paradoxes illustrate. The French origins of this quantitative approach have their roots in philosophical ideas to which few modern day practitioners of the quantitative method subscribe in undiluted form, but that still influence their interpretative preferences. The aesthetic ideal that partly drives the search for simplicity in quantitative analysis leads us to far more basic principles than we had ever expected or might have been searching for. And, time and again, all our knowledge, acquired through counting and calculating and applied for the greater good of the public, runs up against a wall of numerical ignorance the study of which can earn one a Nobel prize-but that ultimately sets binding constraints on the application of the results of public health research.

Funding: none.

Conflicts of interest: none declared.

\section{REFERENCES}

1 Deligeorges S. Le pendule de Foucault au Panthéon. Paris: Caisse National des Monuments Historiques et des Sites, 1995.

2 MacTutor History of Mathematics Archive. School of Mathematical and Computational Sciences, University of St Andrews, Fife, Scotland. http:// turnbull.mcs.st-and.ac.uk/history/ (accessed 28 May 2003).

3 Laberge AF. Edwin Chadwick and the French connection. Bull Hist Med 1988;62:23-41.

4 Laberge A. The early-nineteenth-century French public health movement: the disciplinary development and institutionalization of 'hygiène publique'. Bull Hist Med 1984;58:363-79.

5 Russell B. History of western philosophy, and its connection with political and social circumstances from the earliest times to the present day. London: George Allen and Unwin, 1946.

6 Payer L. Medicine and culture. Varieties of treatment in the United States, England, West-Germany, and France. Harmondsworth: Penguin Books, 1989.

7 Kruijshaar ME, Barendregt JJ, Hoeymans N. The use of models in the estimation of disease epidemiology. Bull World Health Organ 2002;80:622-8.

8 Stewart I. Life's other secret: the new mathematics of the living world. New York: Wiley, 1998.

9 Mankiewicz R. The story of mathematics. London: Cassel, 2000.

10 Mackenbach JP, Kunst AE, Looman CWN. Seasonal variation in mortality in the Netherlands. J Epidemiol Community Health 1992;46:261-5.

11 O'Connor JJ, Rovertson EF. Benjamin Gompertz. In: MacTutor History of Mathematics Archive. Fife: School of Mathematical and Computational Sciences, University of St Andrews, Fife. http://turnbull.mcs.st-and.ac.uk/ history/ (accessed 28 May 2003).

12 Olshansky SJ, Carnes B. The quest for immortality. Science at the frontiers of aging. New York: Norton, 2001.

13 Kirkwood T. Time of our lives. The science of human aging. Oxford: Oxford University Press, 1999

14 Paulos JA. Innumeracy: mathematical illiteracy and its consequences. New York: Hill and Wang, 1988.

15 The Bank of Sweden. Prize in Economic Sciences in Memory of Alfred Nobel 2002. http://www.nobel.se/economics/laureates/2002 (accessed 23 Dec 2002).

16 Tversky A, Kahneman D. Judgement under uncertainty: heuristics and biases. Science 1974; 185:1124-31.

17 Rosen G. A history of public health. New York: MD Publications, 1958.

\section{Making Health Care Safer 2004}

21-22 October 2004

Royal College of Physicians, London

A two day conference for all professionals dedicated to providing safer health care for all. Register now! Early booking discount available.

See website for details: www.quality.bmipg.com 